\title{
Individual differences in action co-representation: not personal distress or subclinical psychotic experiences but sex composition modulates joint action performance
}

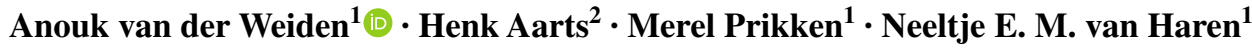

Received: 14 July 2015 / Accepted: 14 October 2015 / Published online: 2 November 2015

(C) The Author(s) 2015. This article is published with open access at Springerlink.com

\begin{abstract}
Successful social interaction requires the ability to integrate as well as distinguish own and others' actions. Normally, the integration and distinction of self and other are a well-balanced process, occurring without much effort or conscious attention. However, not everyone is blessed with the ability to balance self-other distinction and integration, resulting in personal distress in reaction to other people's emotions or even a loss of self [e.g., in (subclinical) psychosis]. Previous research has demonstrated that the integration and distinction of others' actions cause interference with one's own action performance (commonly assessed with a social Simon task). The present study had two goals. First, as previous studies on the social Simon effect employed relatively small samples $(N<50$ per test), we aimed for a sample size that allowed us to test the robustness of the action interference effect. Second, we tested to what extent action interference reflects individual differences in traits related to self-other distinction (i.e., personal distress in reaction to other people's emotions and subclinical psychotic symptoms). Based on a questionnaire study among a large sample $(N=745)$, we selected a subsample $(N=130)$ of participants scoring low, average, or high on subclinical psychotic symptoms, or on personal distress. The selected participants performed a social Simon task. Results showed a robust social Simon effect, regardless of individual differences in personal distress or
\end{abstract}

Anouk van der Weiden

a.vanderweiden@umcutrecht.nl

1 Brain Center Rudolf Magnus, University Medical Center Utrecht, Huispostnummer A.01.126, PO Box 85500, 3508 GA Utrecht, The Netherlands

2 Department of Psychology, Utrecht University, Heidelberglaan 1, 3584 CS Utrecht, The Netherlands subclinical psychotic symptoms. However, exploratory analyses revealed that the sex composition of interaction pairs modulated social Simon effects. Possible explanations for these findings are discussed.

Keywords Joint action · Simon effect · Self-other distinction $\cdot$ Subclinical psychotic symptoms $\cdot$ Personal distress $\cdot$ Sex composition

\section{Introduction}

As social beings, we develop great expertise in reading other people's intentions, actions, and emotions. This ability has been linked to the so-called mirror neuron network, which is dedicated to understanding and anticipating own as well as others' actions and emotions (Cattaneo and Rizzolatti 2009; Gallese and Goldman 1998; Goldman 1989, 2009; Kilner et al. 2007; Meyer et al. 2011; Mukamel et al. 2010; Ocampo and Kritikos 2011). It allows people to take into account, or integrate, the actions and emotions of others and to react accordingly (e.g., to pass someone on the right when that person is going left, or to offer consolation when someone is feeling sad). Crucially, this neural network that allows self-other integration also allows people to distinguish own and others' actions and emotions, as it is generally more active for own compared with others' actions and emotions (Mukamel et al. 2010). In the present study, using a well-documented complementary action task that taps into these self-other integration and distinction processes (Dolk et al. 2013; Sartori and Betti 2015; Sebanz et al. 2003), we investigate the robustness of self-other distinction in social interaction, as well as its susceptibility to individual differences in traits related to self-other distinction. 
The extent to which people integrate and distinguish self and other in social interaction has been extensively examined by using the joint (or social) Simon task. In a typical Simon task (Craft and Simon 1970), participants respond with left and right key presses to stimuli (e.g., red and green dots) that are presented to the left or to the right of the computer screen. This task requires people to distinguish left and right actions in terms of action planning and execution. As a consequence of this "left" versus "right" distinction, participants generally respond slower to stimuli that are spatially incongruent (e.g., pressing a left key in response to stimuli presented to the right). This interference effect is typically absent in a go/no-go version of the task where participants only have to respond to one of the stimuli (Hommel 1996; Sebanz et al. 2003). Intriguingly, when two participants each respond to one of the stimuli in a joint go/no-go Simon task, this reinstates the action interference effect. This reinstatement of the action interference effect is also known as the social Simon effect and reflects the extent to which one represents own actions in spatial reference to one's co-actor (e.g., as "left" as opposed to "right"), resulting in slower reaction times to stimuli that are spatially incongruent with this representation (e.g., presented to the right; Dolk et al. 2013, 2014; Ferraro et al. 2011; Obhi and Sebanz 2011; Sebanz et al. 2003). Recent research shows that people may also use other (nonspatial) reference frames, such as color or identity (Philipp and Prinz 2010; Sellaro et al. 2015).

The social Simon effect varies in strength, partly due to the relatively small samples (usually around 20, with the highest $N$ being 48 to our knowledge; Stenzel et al. 2013) that have been used in earlier work (Dolk et al. 2011; Ruys and Aarts 2010; Sebanz et al. 2003; Vlainic et al. 2010). Another reason for the variation in the strength of the social Simon effect pertains to the observation that the effect depends on contextual as well as individual differences (Aron et al. 1992; Colzato et al. 2012a, b, 2013; Decety and Sommerville 2003; Humphreys and Bedford 2011; Müller et al. 2011; Slotter and Gardner 2009). That is, although the social Simon effect is not necessarily a social effect (Dolk et al. 2013), it does depend on the social context. Specifically, the effect is stronger for similar versus dissimilar others, e.g., in terms of cognitive style (McClung et al. 2013), ethnicity (Müller et al. 2011) or perceived agency (Müller et al. 2011; Stenzel et al. 2012, 2014). Similarly, a focus on similarities or integration enhances the effect. For example, previous research suggests that convergent versus divergent thinking increases the social Simon effect (Colzato et al. 2013). Also, Buddhists who tend to integrate others more than atheists show a larger social Simon effect (Colzato et al. 2012). Thus, the social Simon effect may be regarded as an objective measure of self-other integration.

Although higher levels of self-other integration may help people cope better with threats (Castano et al. 2002) and increase compassion (Valdesolo and DeSteno 2011) and cooperation (Vesper et al. 2011; Wiltermuth and Heath, 2009), it may also be disturbing. For example, the simulation of (especially negative) emotions of others may result in personal distress, as can also be witnessed in occurrences of mass panic (Decety and Lamm 2011). Also, too much self-other integration may blur self-other boundaries and lead to a feeling of loss of self, which is a core characteristic of schizophrenia (Hur et al. 2014; Johns et al. 2001; Maeda et al. 2012; Mishara et al. 2014; Nelson et al. 2014; Renes et al. 2015; van der Weiden et al. 2015), and is also present in individuals with subclinical positive psychotic symptoms (Asai et al. 2011, 2008; Asai and Tanno 2008). Specifically, many (subclinical) psychotic symptoms (e.g., delusions of control, auditory hallucinations, grandiose delusions, and delusions of reference) reflect difficulties in distinguishing one's own thoughts, emotions, intentions, and actions from those of others. For example, people may feel their actions are being controlled by others (i.e., delusions of control; Frith 2005; Stefanis et al. 2002).

To assess the extent to which experiences of personal distress in reaction to other people's emotions and (subclinical) psychotic experiences reflect excessive integration of self and other, we aimed to test (1) the robustness of the social Simon effect, and (2) whether individual differences in personal distress and subclinical psychotic symptoms are reflected in enhanced social Simon effects. We expect that individuals who score high on personal distress or subclinical psychotic experiences integrate the other person's actions too much (and distinguish too little), resulting in larger action interference, compared to those who score low or average on these traits. Conversely, people who score low on personal distress or subclinical psychotic symptoms may also show a weaker action interference effect than people who score average on these traits.

\section{Methods}

\section{Ethics statement}

This study has been approved by the local ethics committee and has therefore been performed in accordance with the ethical standards laid down in the 1964 Declaration of Helsinki. All participants gave their informed consent prior to their inclusion in the study.

\section{Participants and design}

\section{Participant recruitment}

We administered two questionnaires in a large sample of young adults $\left(N=745 ; M_{\text {age }}=20.88, \mathrm{SD}_{\text {age }}=2.37\right)$ to 
Fig. 1 Descriptive statistics for the two subscales for the total and subsample

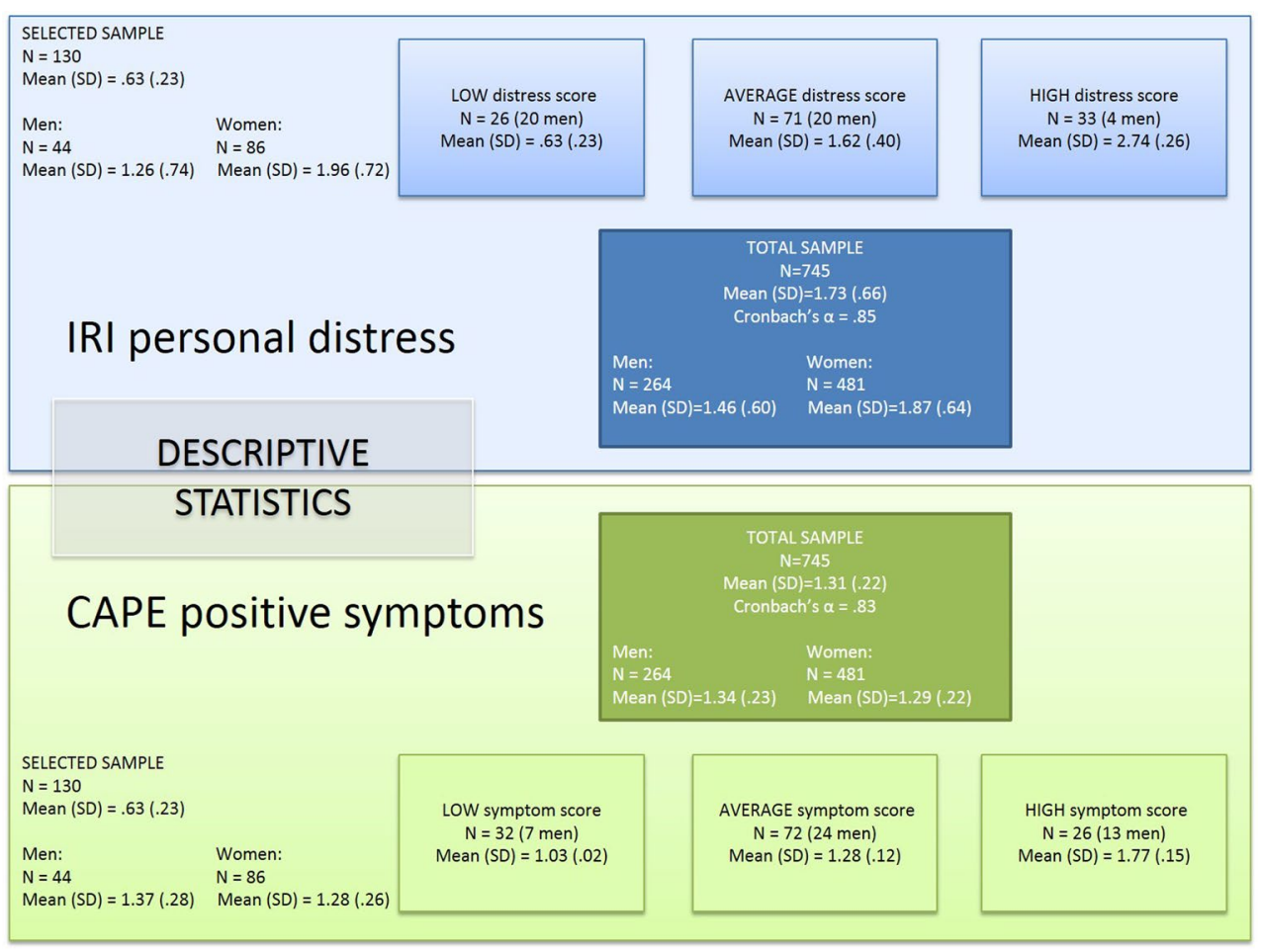

recruit participants scoring low versus high on personal distress and subclinical psychotic symptoms. For this purpose, we first administered the personal distress subscale as part of the Interpersonal Reactivity Index (IRI; Davis 1980, 1983), which assesses personal distress in reaction to other people's emotions. This subscale consists of seven items that can be rated on a 5-point scale, ranging from 0 [does not describe me well] to 4 [describes me very well]. Example items are: "I sometimes feel helpless when I am in the middle of a very emotional situation" and "When I see someone who badly needs help in an emergency, I go to pieces." The other subscales concern perspective-taking ability (perspective-taking subscale) and the ability to empathize with other people (empathy subscale) as well as fictive characters (fantasy subscale). Secondly, the severity of subclinical psychotic symptoms was assessed using the positive subscale of the Community Assessment of Psychic Experiences (CAPE; Stefanis et al. 2002). The positive subscale consists of 20 items that can be rated on a 4-point scale, ranging from 1 [never] to 4 [almost constant]. Example items are: "Have you ever felt as if the thoughts in your head are not your own?" and "Have you ever felt as if you are under the control of some force or power other than yourself?" The other subscales assess negative symptoms (i.e., absence of normal thoughts, feelings, and behaviors, e.g., affective flattening, apathy, anhedonia, and avolition) and symptoms of depression. Based on participants' personal distress and positive psychotic symptom scores, we selected a subsample of participants $(N=130$;
$M_{\text {age }}=20.68, \mathrm{SD}_{\mathrm{age}}=2.43$ ) who scored low (lower than 1 SD from the total sample mean), average (equals total sample mean), or high (higher than 1 SD from the total sample mean) on either of these traits. All selected participants had normal or corrected-to-normal vision and were naïve to the purpose of this study. ${ }^{1}$ The large sample size (2.7 times larger than the largest sample size of 48) of our study allows us to test the robustness of the social Simon effect.

\section{Total sample}

Figure 1 presents the descriptive statistics for the total sample. In line with previous research (Davis 1980; Michalska et al. 2013), women scored on average .41 higher on personal distress than men, with a $95 \%$ CI of $(.32, .51)$, $t(742)=8.57, p<.001$, Cohen's $d=.66$. Furthermore, men scored on average .05 higher on positive symptoms than women, with a $95 \%$ CI of $(.02, .09), t(740)=3.06$, $p=.002$, Cohen's $d=.24$.

\footnotetext{
${ }^{1}$ Unfortunately we did not determine handedness, but as participants were free to use their left or right hand for responding, and seating location did not affect our results, we believe it is not very likely that the dominance of handedness had a substantial influence on our results.
} 


\section{Selected subsample}

As participants filled in both questionnaires, they could end up in two of these groups (e.g., low on both traits; or low on one and high on the other trait). Importantly, the scores on the two subscales were not correlated, $r(130)=-.08$, $p=.34$. However, most participants who fell within one of the extreme groups (either high or low) of one trait had an average score on the other trait. Hence, the average groups were larger in sample size. See Fig. 1 for the descriptive statistics. The distributions of the selected samples did not differ from the total sample (no difference between selected and unselected participants as indicated by independent samples Mann-Whitney $U$ tests: $p=.87$ for IRI $\mathrm{distress}_{\text {and }}$ $p=.41$ for $\mathrm{CAPE}_{\text {positive }}$ ). We therefore chose to analyze IRI and CAPE scores as continuous predictors.

Even more pronounced than in the whole sample $\left(F(3,740)=7.39, p=.01, \eta_{p}^{2}=.01\right)$, women scored on average .70 higher on personal distress than men, with a $95 \%$ CI of $(.43, .97), t(127)=5.15, p<.001$, Cohen's $d=.97$. Sex differences in psychotic symptoms were less pronounced in the selected sample, with men scoring only .09 higher on average than women, with a $95 \%$ CI of $(-.01, .19), t(127)=1.76, p=.08$, Cohen's $d=.33$. Consequently, there were only a small number of women

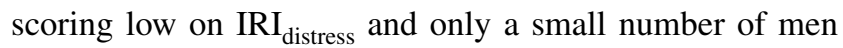
scoring high on IRI $\mathrm{distress}_{\text {in }}$ our selected sample. Similarly, there were only a small number of men scoring low on $\mathrm{CAPE}_{\text {positive }}$ in our selected sample.

We performed separate analyses for personal distress and subclinical psychotic symptoms. The experiment thus had a 1 (trait: $\mathrm{CAPE}_{\text {positive }}$ or IRI $\mathrm{Idistress}_{\text {) }}$ by 2 (congruency: congruent vs. incongruent) mixed design, with trait as a continuous between-subjects variable and congruency as within-subjects variable. Because of sex differences on the IRI $_{\text {distress }}$, we also included sex as a between-subjects variable in the analyses involving IRI $\mathrm{distress}_{\text {. }}$

\section{Experimental task and procedure}

Participants were invited to the laboratory in random pairs to perform the validated and well-documented social Simon task to measure joint action interference (Sebanz et al. 2003). Mixed sex pairs were possible. The only criterion was that participants did not know each other. In case one of the participants in a pair did not show up, a research confederate performed his or her part of the task. In the social Simon task, participants sat next to each other as they responded to colored dots (i.e., red or green) on the computer screen. Each person was responsible for responding to only one of the two colors. For example, if the dot is red, the participant on the left presses the left button, and when the dot is green, the participants on the right press the right button (or vice versa). The location of the displayed dot was varied (left or right on the computer screen) to be congruent or incongruent with the subject's location and button press. That is, the participant sitting on the left responded by pressing the " $Z$ " on the left side of a QWERTY keyboard, and the participants sitting on the right responded by pressing " 3 " on the right numerical side of the same keyboard.

At the beginning of each trial, participants saw a rectangular frame containing three circles (see Fig. 2 for an illustration of a trial). After $500 \mathrm{~ms}$, one of these circles would turn either red or green for $150 \mathrm{~ms}$. Depending on the color, either the participant on the left or the participant on the right had to respond as fast as possible, whereas the other participant had to refrain from responding. Once the participant had responded, the next trial would begin after a 1000-ms inter-trial interval.

The task consisted of 2 blocks of 45 trials each. In 20 of these trials, the location of the presented colored dot (e.g., green, left) was consistent with participants' location and button press (i.e., left). In another 20 trials, the location of the colored dot (e.g., right) was inconsistent with participants' location and button press (i.e., left). The remaining five trials were filler trials, in which the colored dot was presented in the middle. Trials were randomly presented. After the first block, the target color to which participants had to respond was counterbalanced. That is, participants who were responding to the color green in the first block had to respond to the color red in the second block, and vice versa.

\section{Results}

Responses below $100 \mathrm{~ms}$ or above $1000 \mathrm{~ms}$ were removed (Ratcliff 1993). As color and seating location did not interact with congruency (all $F \mathrm{~s}<1.96$ ), IRI distress $_{\text {(all }}$ $F \mathrm{~s}<1.96$ ), $\mathrm{CAPE}_{\text {pos }}$ (all $F \mathrm{~s}<2.66$ ), or participants' sex (all $F$ s $<1.08)$ in any of the analyses reported below, we computed mean RTs (in ms) on congruent and incongruent trials, collapsing across target color and seating location. In 32 cases, a confederate played the part of co-actor. Importantly, this did not interact with the congruency effects reported below (all $F$ s $<2.16$ ). We subjected participants' mean RTs to two separate 2 (congruency: incongruent vs. congruent) by 1 (standardized continuous trait score) repeated measures ANOVAs: one for personal distress and one for subclinical psychotic symptoms. Because of sex differences in self-reported personal distress, we further included participants' sex as a between-participants factor in the personal distress analyses. 
Table 1 Statistical analyses for congruency, IRI $\mathrm{d}_{\text {distress }}$, and participants' sex

\begin{tabular}{|c|c|c|c|c|c|c|c|c|c|c|c|c|}
\hline \multirow[t]{2}{*}{ Error $d f=126$} & \multicolumn{3}{|c|}{ Total sample } & \multicolumn{3}{|c|}{ Low IRI distress $_{\text {. }}$} & \multicolumn{3}{|c|}{ High IRI $_{\text {distress }}$} & \multicolumn{3}{|c|}{$\begin{array}{l}\text { Low versus high } \\
\text { IRI }_{\text {distress }}\end{array}$} \\
\hline & $F$ & Sig. & $\eta_{p}^{2}$ & $F$ & Sig. & $\eta_{p}^{2}$ & $F$ & Sig. & $\eta_{p}^{2}$ & $F$ & Sig. & $\eta_{p}^{2}$ \\
\hline Congruency & 54.38 & $<.001$ & .30 & 27.87 & $<.001$ & .18 & 38.94 & $<.001$ & .24 & 4.30 & .04 & .03 \\
\hline Men & 41.90 & $<.001$ & $.50^{\mathrm{a}}$ & 12.40 & .001 & .09 & 24.89 & $<.001$ & .17 & 14.11 & .001 & $.25^{\mathrm{b}}$ \\
\hline Women & 24.43 & $<.001$ & $.23^{\mathrm{a}}$ & 15.47 & $<.001$ & .11 & 16.88 & $<.001$ & .12 & .49 & .49 & $.01^{\mathrm{c}}$ \\
\hline Men versus women & 3.10 & .08 & .02 & .30 & .58 & .002 & 8.10 & .005 & .06 & 8.76 & .004 & .07 \\
\hline \multicolumn{13}{|l|}{ a $d f=128$} \\
\hline \multicolumn{13}{|l|}{ b $d f=42$} \\
\hline${ }^{c} d f=84$ & & & & & & & & & & & & \\
\hline
\end{tabular}

\section{Confirmatory analyses}

\section{Personal distress}

A repeated measures ANOVA with congruency (incongruent vs. congruent) as within-subjects variable, IRI $_{\text {distress }}$ as standardized continuous predictor, and participants' sex (male vs. female) as between-subjects variable revealed the expected main effect of congruency. Participants were on average $10.07 \mathrm{~ms}$ faster to respond to congruent $(M=314.12, \mathrm{SD}=35.65)$ compared with incongruent $(M=324.19, \mathrm{SD}=36.18)$ stimuli. As expected, there was an interaction between congruency and IRI distress $_{\text {(see }}$ upper right cell in Table 1). However, this interaction was qualified by an unexpected three-way interaction with participants' sex (see lower right cell in Table 1). Figure 3 presents the mean RTs for each cell in the design; Table 1 presents the statistics.

In order to examine this three-way interaction and to test our specific hypothesis, the effect of congruency was assessed for male and female participants scoring low on IRI $_{\text {distress }}$ (one standard deviation below the mean) and for male and female participants scoring high on IRIdistress (one standard deviation above the mean) separately (based on estimated marginal means; see Aiken and West 1991). These analyses revealed that male participants scoring high on IRI $I_{\text {distress }}$ had a larger congruency effect than

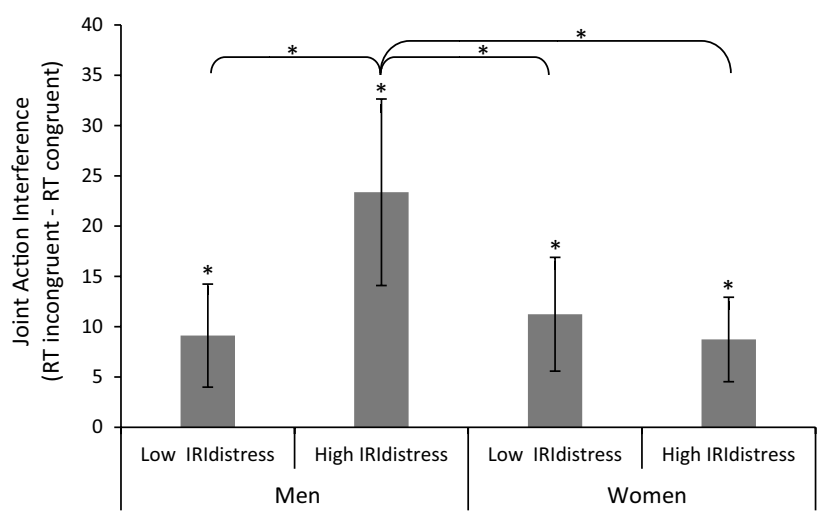

Fig. 3 Joint action interference as a function of participants' sex and individual differences in personal distress in reaction to other people's emotions. Error bars represent $95 \%$ confidence intervals
Fig. 2 Schematic example of a congruent action trial in the social Simon task where the person on the left has to respond to green dots

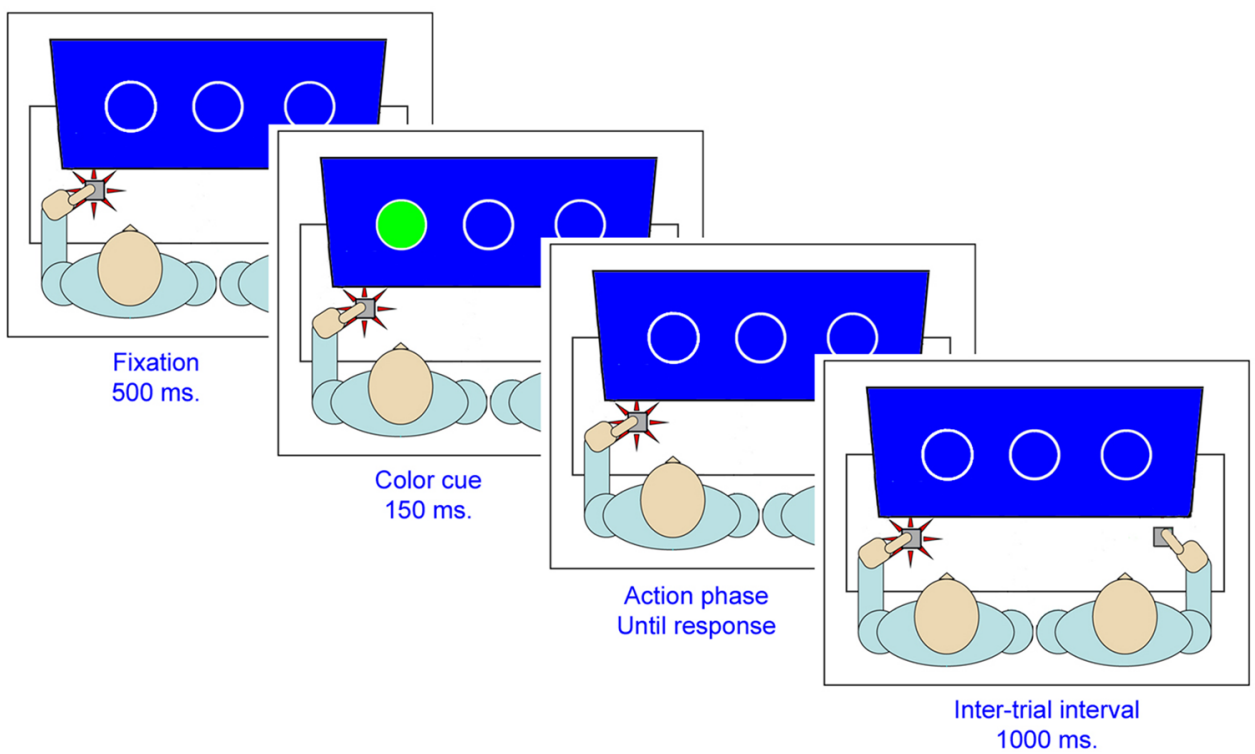


Table 2 Statistical analyses for congruency, $\mathrm{CAPE}_{\text {positive }}$, and participants'sex

\begin{tabular}{lccc}
\hline Error $d f=128$ & $F$ & Sig. & $\eta_{p}^{2}$ \\
\hline Congruency & 44.96 & $<.001$ & .26 \\
$\mathrm{CAPE}_{\text {positive }} * \mathrm{CAPE}_{\text {positive }}$ & 1.63 & .20 & .01 \\
Congruency & .68 & .41 & .01 \\
\hline
\end{tabular}

male participants scoring low on $\mathrm{IRI}_{\text {distress }}$ and female participants in general. However, considering that only a small proportion of males actually scored high $(>1$ SD above the mean) on personal distress, these effects should be interpreted with extreme caution.

\section{Subclinical psychotic symptoms}

A repeated measures ANOVA with congruency (incongruent vs. congruent) as within-subjects variable and $\mathrm{CAPE}_{\text {pos- }}$ itive as standardized continuous predictor again revealed the main effect of congruency. Contrary to our expectations, there were no main or interaction effects with $\mathrm{CAPE}_{\text {positive }}$. Figure 4 presents the mean RTs for each cell in the design; Table 2 presents the statistics.

\section{Exploratory post hoc analyses}

\section{Social Simon effect and the other IRI and CAPE subscales}

As the distribution of the personal distress and positive psychotic symptom scales in the selected sample were normally distributed and did not differ from the total sample, we were also able to explore potential relationships between the other subscales and the social Simon effect. In particular, the perspective-taking subscale of the IRI is potentially interesting as recent research has shown that people show a stronger social Simon effect when they take the perspective of their interaction partner (Ford and Aberdein 2015; Müller et al. 2011a, b, 2015).

To assess the relationship between the social Simon effect and the other subscales, we performed a number of separate repeated measures ANOVAs with congruency (incongruent vs. congruent) as within-subjects variable, and the different subscales as standardized continuous variable. As women scored higher on perspective taking $(t(128)=2.44, p=.02)$, empathy $(t(128)=6.82$, $p<.001)$, and fantasy $(t(128)=2.79, p=.01)$, participant's sex (male vs. female) was also included as betweensubjects variable in the analyses concerning these subscales. These analyses again revealed strong main effects of congruency (all $F_{\mathrm{S}} \geq 30.88$ ), but no interactions between congruency and any of the other subscales (all $F_{\mathrm{S}} \leq 1.75$ ).

\section{Sex composition}

In our study, we included both male and female participants. It has been argued that participants' sex may affect the joint action effect because of in-group/out-group categorization processes (Powlishta 1995). For this purpose, some researchers took sex into account by studying the social Simon effect in matched gender pairs or even including only male or female participants in their studies (Liepelt et al. 2012; McClung et al. 2013; Philipp and Prinz 2010). As far as we know, there is only one study that showed effects of sex composition on the social Simon effect, such that the social Simon effect is stronger in samesex pairs than in opposite-sex pairs (Mussi et al. 2015). Furthermore, sample sizes are usually too small to analyze the effect of sex composition and potential sex differences herein. Because of our relatively large sample size, we are able to provide a first test of sex composition in the joint action effect. In doing so, we controlled for individual differences in IRI $_{\text {distress }}$, as men and women differed on this trait.

Action interference as a function of own and other's sex A repeated measures ANOVA with congruency (incongruent vs. congruent) as within-subjects variable, participant's sex (male vs. female) and partner's sex (male vs. female) as between-subjects variables, and IRI $_{\text {distress }}$ as standardized continuous variable again revealed a strong main effect of congruency, as well as an interaction between congruency and IRI $_{\text {distress }}$, and a three-way interaction with participants' sex. Additionally, the analysis revealed an interaction between congruency and participants' sex, which was qualified by a reliable three-way interaction of congruency, participant's sex, and partners' sex. See Table 3 for the statistics.

To gain further insight into this three-way interaction, we performed simple effects analyses. To corroborate the recent findings of Mussi et al. (2015), we first analyzed the social Simon effect as a function of same-sex versus opposite-sex pairing. These analyses revealed that although there was an effect of congruency for both same-sex and opposite-sex pairs, the congruency effect was larger by $6.75 \mathrm{~ms}$ for same-sex pairs $(M=12.71, \mathrm{SD}=17.23) \mathrm{com}-$ pared with opposite-sex pairs $(M=5.97, \mathrm{SD}=16.39)$, $95 \%$ CI $(.74,12.76)$. To further inspect this two-way interaction, we performed further simple effects analyses to investigate the effect of congruency and sex composition within women and men separately.

For women, a reliable two-way interaction emerged between partners' sex and congruency. On average, women responded $12.81 \mathrm{~ms}$ faster to congruent $(M=313.04$, $\mathrm{SD}=33.68)$ compared with incongruent $(M=324.89$, $\mathrm{SD}=33.99)$ stimuli with a $95 \%$ CI of $(7.24,16.46)$ when 
Table 3 Statistical analyses for congruency, participants' sex, partners' sex, and IRI distress $_{\text {s }}$

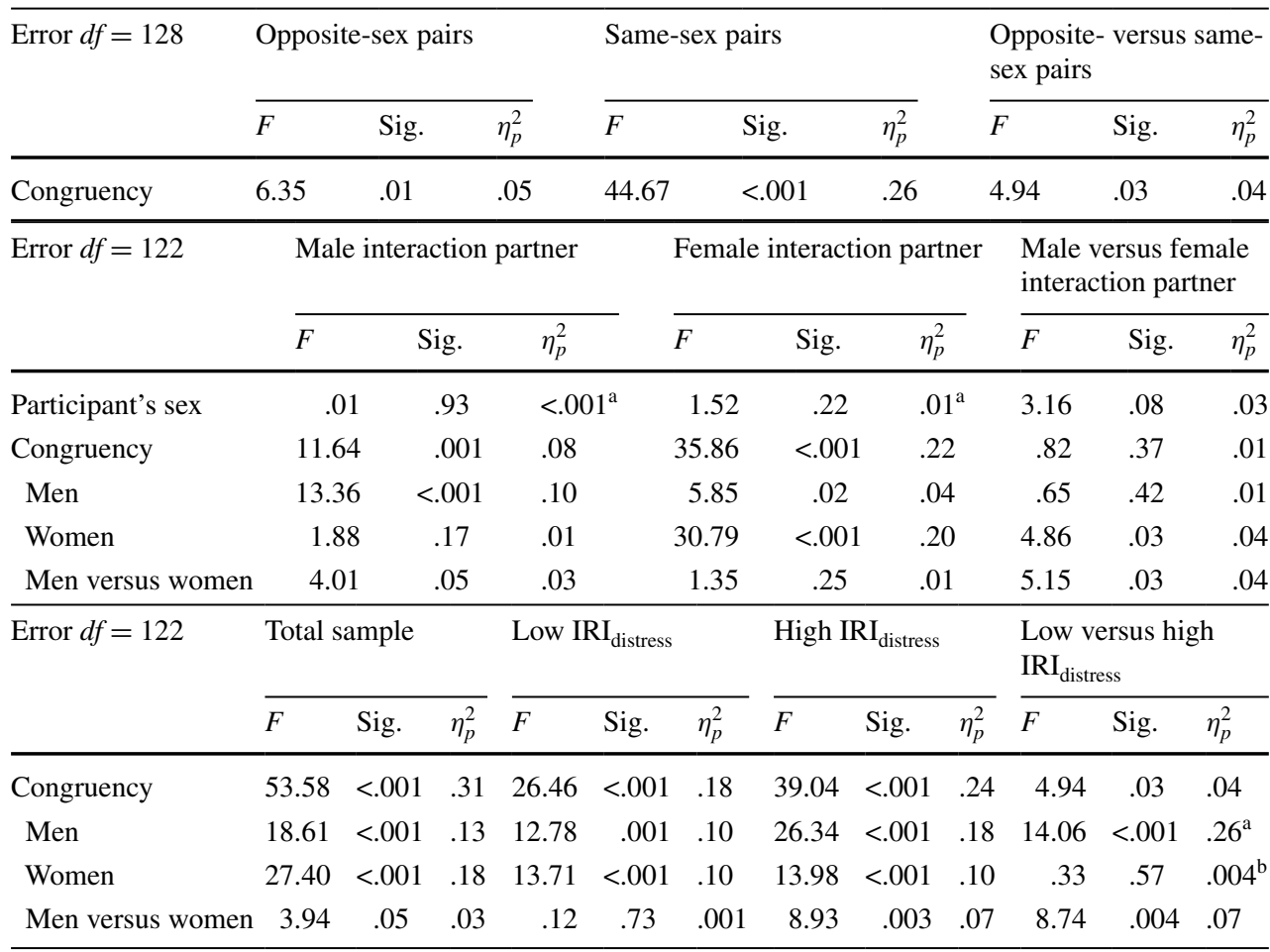

a $d f=125$

b $d f=126$

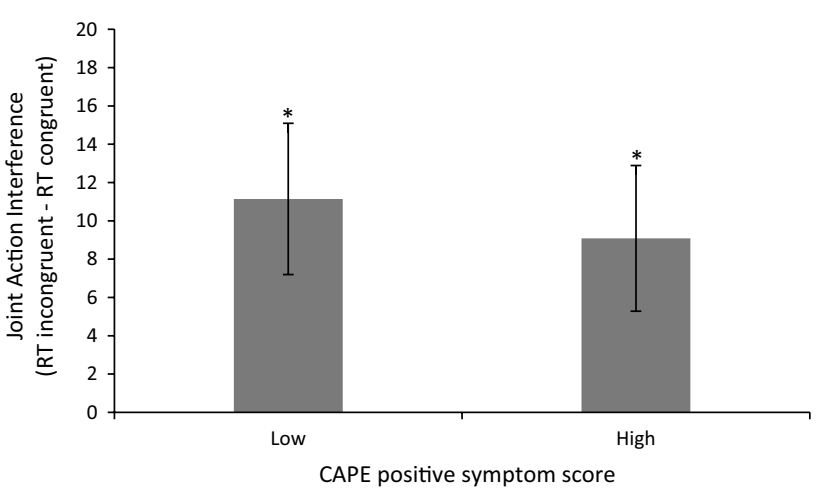

Fig. 4 Joint action interference as a function of participants' sex and individual differences in subclinical psychotic symptoms (based on estimated marginal means). Error bars represent $95 \%$ confidence intervals

they interacted with another woman. When they interacted with a man, RTs did not differ for congruent $(M=314.40$, $\mathrm{SD}=37.76)$ and incongruent $(M=319.00, \mathrm{SD}=34.49)$ stimuli, $95 \%$ CI $(-2.34,11.54)$.

For men, there was no statistically significant interaction between partners' sex and congruency. Men responded $11.03 \mathrm{~ms}$ faster on average to congruent $(M=315.39$, $\mathrm{SD}=37.66)$ compared with incongruent $(M=326.42$, $\mathrm{SD}=40.33)$ stimuli $[95 \% \mathrm{CI}(6.21,15.85)]$, regardless of

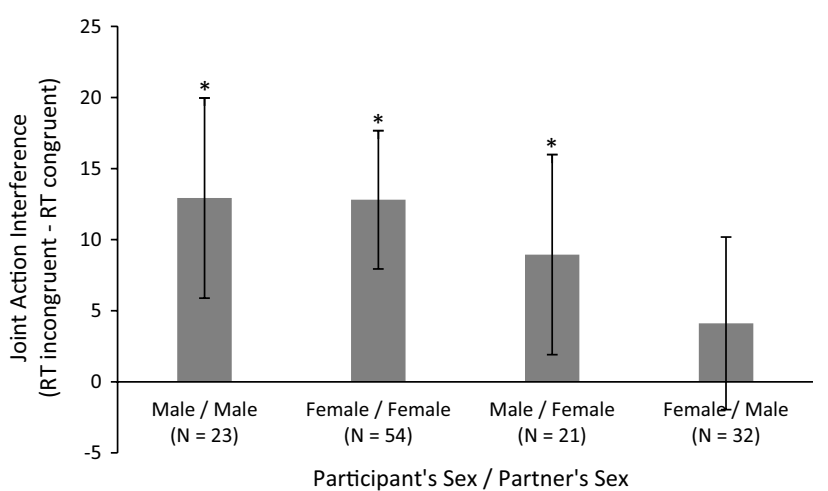

Fig. 5 Joint action interference for the different compositions of pairs in terms of participant's sex and interaction partner's sex. Note that the number of men performing the task with a female co-actor differs from the number of women performing the task with a male co-actor. This is due to the occasional interaction with a research confederate rather than another participant as a co-actor. Error bars represent $95 \%$ confidence intervals

their interaction partner's sex. Figure 5 presents the mean RTs for each cell in the design.

Reaction times as a function of own and other's sex The repeated measures ANOVA further revealed a statistically nonsignificant interaction effect between participants' sex and partners' sex. Specifically, male participants interact- 


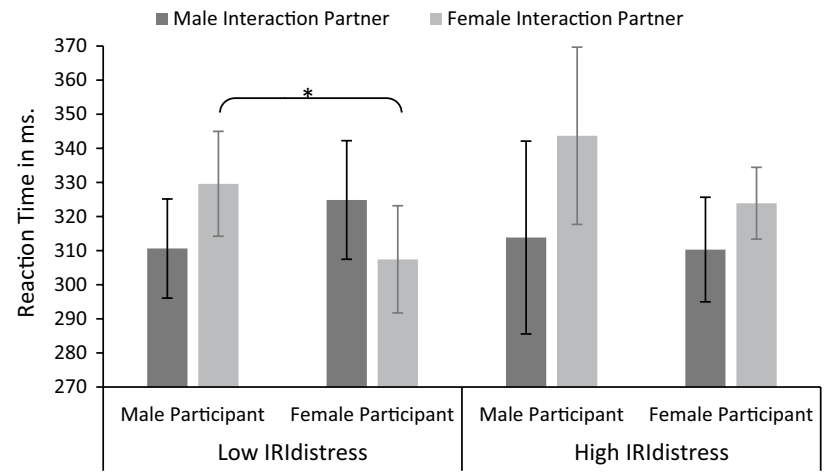

Fig. 6 Mean reaction times as a function of IRI $I_{\text {distress }}$ score, participant's sex, and interaction partner's sex. Error bars represent $95 \%$ confidence intervals

ing with a female partner seem to perform much slower $(M=331.78, \mathrm{SD}=45.40)$ compared with male participants interacting with a male partner $(M=310.99, \mathrm{SD}=29.63)$ and female participants in general $(M=317.91, \mathrm{SD}=34.42)$. This interaction seems to mainly be driven by a decrease in reaction time for men interacting with women and is slightly stronger for participants scoring low on IRI $\mathrm{distress}_{\text {than }}$ for

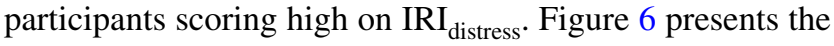
mean reaction times as a function of participants' sex, partners' sex, and IRI $\mathrm{distress}_{\text {. }}$.

\section{Discussion and conclusion}

The present study examined the effect of individual differences in level of experienced personal distress and subclinical psychotic symptoms on action interference in joint action. As expected, we replicated the basic social Simon effect in a large sample $(N=130)$, speaking for the robustness of the effect. In contrast to our hypotheses, individual differences in subclinical psychotic symptoms and interpersonal distress did not seem to reliably affect action interference effects in joint action. Although there was a statistically significant interaction between interpersonal distress and joint action interference, this interaction was only driven by a small subsample of male participants and should thus be interpreted with caution. Finally, exploratory analyses revealed that action interference depended on the gender composition of interaction pairs.

\section{Personal distress}

The present findings seem to suggest that although people who tend to experience distress in reaction to other people's emotions may have difficulty in distinguishing own and others' emotions (Lamm et al. 2007b), they do not necessarily struggle with distinguishing own and others' actions (see also Ford and Aberdein 2015). This may be because others' emotions are typically more salient than the neutral and irrelevant actions of the interaction partner in our experimental setup. If so, increasing the salience of the interaction partners' actions may result in stronger action interference. In line with this notion, recent research has indicated that action interference reduces as the action event becomes less social and less salient (Dolk et al. 2013; Klempova and Liepelt 2015).

Furthermore, the integration of own and others' actions involves different brain areas than the integration of own and others' emotions (Carr et al. 2003; Cochin et al. 1998; Hari et al. 1998; Iacoboni 2009; Mukamel et al. 2010; Rizzolatti and Craighero 2005). That is, while the observation of others' actions and emotions activates overlapping brain areas in the mirror neuron network, the observation of others' emotions additionally activates areas in the limbic system (Carr et al. 2003; Hefner et al. 2008; Lamm et al. 2007a; Muigg et al. 2008). Although the limbic system is involved in the understanding and performance of emotion-laden actions (e.g., scoring a goal in a soccer game; Hajcak et al. 2007; Mogenson et al. 1980), it may not be involved in the understanding and performance of neutral actions (e.g., pressing a left button in response to a green dot). Hence, variability in experiencing distress in reaction to other people's emotions may be related to specific processes in the limbic system and may only affect the coordination of emotion-laden actions.

\section{Subclinical psychotic symptoms}

People who scored relatively high on subclinical psychotic symptoms also did not seem to have difficulty distinguishing own and others' actions. Whereas previous work has found relations between subclinical psychotic symptoms and the sense of agency over action (Asai and Tanno 2008; Hauser et al. 2011; Sugimori et al. 2011; but see Jones et al. 2008), the present findings indicate that these relations cannot be generalized to self-other distinction at the behavioral level. However, it is important to note that even in the "high" subclinical psychotic symptoms group, psychotic experiences were still infrequent (1.77 on average with 1 being "never"). This is in line with the notion that although subclinical positive symptoms are highly prevalent in the general population (around 100 times greater than clinical psychosis), these symptoms are usually not persistent (Hanssen et al. 2005). The chance of observing a relation between subclinical positive symptoms and joint action performance might thus be bigger if they would be assessed over a shorter time span.

Another direction for future research is to further examine joint action performance in individuals with a more stable and/or severe condition, such as in people with 
schizotypal personality traits or in patients with schizophrenia. So far, only one study has been conducted that examined the action interference effect in schizophrenia patients (Liepelt et al. 2012). Results indicated that schizophrenia patients do not experience any interference from their interaction partner's actions. This lack of action interference may reflect a lack of co-representing (or integrating) the partners' actions, or alternatively an inability to distinguish between own and others' actions based on spatial cues (Dolk et al. 2013). Either of these impairments would undermine successful action coordination. For example, a lack of integration might actually facilitate one's own action performance (e.g., throwing a ball), but would impede joint action performance (e.g., throwing a ball in such a way that one's friend can catch it and throw it back). However, a lack of distinction would impede one's own action performance as well as joint action performance (e.g., making a throwing movement when one should catch the ball). Hence, it would be interesting for future research to examine whether the absence of action interference in schizophrenia patients results from a lack of integration of and/or distinction between own and others' actions.

\section{Other IRI and CAPE subscales}

Although previous research has demonstrated that the social Simon effect is generally stronger when people take the perspective of their interaction partner (Müller et al. 2011a, b, 2015), we were unable to pick up this effect when using a self-report questionnaire that assesses people's tendency to take the perspective of others in daily life. This converges with recent evidence that the social Simon effect is only modulated by self-reported empathy when interacting with a friend, and not when interacting with a stranger (Ford and Aberdein 2015). These findings suggest that perspective-taking ability is not sufficient to enhance the social Simon effect. That is, whether this ability is actually deployed also depends on the context, e.g., whether one's interaction partner is a friend (Ford and Aberdein 2015), or whether one is explicitly instructed to take the perspective of one's interaction partner (Müller et al. 2011a, b, 2015). Similarly, the social Simon effect may be more susceptible to state manipulations of empathy, fantasy, or personal distress than individual trait differences herein.

\section{Sex composition}

Replicating and extending recent work (Mussi et al. 2015), our exploratory analyses indicated that the sex composition of interaction pairs modulated action interference effects. First of all, although this effect has to be interpreted with caution, there was a trend for men to be overall faster when interacting with men compared with women. This may be either because men tend to get distracted by women (Duncan et al. 2007; van Hooff et al. 2011; Zhang and Deng 2014), or because men are more competitive when interacting with another man (Cashdan 1998; Freischlag 1973). These processes may also have played a role in the action interference effects. That is, men showed an action interference effect, regardless of their interaction partners' sex. However, these action interference effects may have resulted from different processes, since action interference is enhanced by attention (Dittrich et al. 2012) as well as competition (Ruys et al. 2010). It is thus important to consider the sex of participants as well as their interaction partners if we want to better understand the underlying mechanisms of and implications for social interaction.

This is also reflected in the observation that women only experienced action interference when interacting with another woman, while they experienced no action interference when interacting with men. This suggests that women either do not integrate or very effectively distinguish the actions of unknown men, supporting the notion that sex may instigate in-group/out-group categorization processes (Powlishta 1995). In line with this notion, action interference effects in general were stronger for same-sex pairs compared with opposite-sex pairs. Importantly, as only women showed an absence of the action interference effect when interacting with an interaction partner of the opposite sex, there may be factors that modulate this effect, such as an actor's sexual goals (Aarts et al. 2004; Karremans and Verwijmeren 2008; Petersen and Hyde 2010). For example, recent research suggests that people who are involved in a romantic relationship are less inclined to mimic the behaviors of opposite-sex others (Karremans and Verwijmeren 2008). If women in our sample were more often involved in romantic relationships than men, this may explain the specific absence of an action interference effect for women interacting with men. Furthermore, men may be more attentive to women because they more often pursue casual sex than women (Clark and Hatfield 1989; Ickes 1993; Leitenberg and Henning 1995). It would be interesting for future research to address the role of gender as well as relationship status in joint action interference.

In conclusion, the present study suggests that individual differences in personal distress and subclinical psychotic symptoms do not reliably affect the performance of neutral, complementary actions. However, extending recent research (Mussi et al. 2015), we provided a first, exploratory test of different sex compositions in joint action performance. Although the present findings have to be interpreted with caution and need to be replicated in future research, they suggest that it is important to consider the sex of participants as well as their interaction partners if we want to better understand the underlying mechanisms of and implications for social interaction. 
Acknowledgments The work in this paper was supported by VIDI-Grant 452-11-014 from the Dutch Organization for Scientific Research.

\section{Compliance with ethical standards}

Ethical approval All procedures performed in studies involving human participants were in accordance with the ethical standards of the institutional and/or national research committee and with the 1964 Helsinki Declaration and its later amendments or comparable ethical standards.

Informed consent Informed consent was obtained from all individual participants included in the study.

Open Access This article is distributed under the terms of the Creative Commons Attribution 4.0 International License (http://creativecommons.org/licenses/by/4.0/), which permits unrestricted use, distribution, and reproduction in any medium, provided you give appropriate credit to the original author(s) and the source, provide a link to the Creative Commons license, and indicate if changes were made.

\section{References}

Aarts H, Gollwitzer PM, Hassin RR (2004) Goal contagion: perceiving is for pursuing. J Pers Soc Psychol 87(1):23-37. doi:10.1037/0022-3514.87.1.23

Aiken LS, West SG (1991) Multiple Regression: Testing and interpreting interactions. CA: Sage, Newbury Park

Aron A, Aron EN, Smollan D (1992) Inclusion of Other in the Self Scale and the structure of interpersonal closeness. J Pers Soc Psychol 63(4):596-612

Asai T, Tanno Y (2008) Highly schizotypal students have a weaker sense of self-agency. Psychiatry Clin Neurosci 62(1):115-119. doi:10.1111/j.1440-1819.2007.01768.x

Asai T, Sugimori E, Tanno Y (2008) Schizotypal personality traits and prediction of one's own movements in motor control: What causes an abnormal sense of agency? Conscious Cogn 17(4):1131-1142. doi:10.1016/j.concog.2008.04.004

Asai T, Mao Z, Sugimori E, Tanno Y (2011) Rubber hand illusion, empathy, and schizotypal experiences in terms of self-other representations. Conscious Cogn 20(4):1744-1750. doi:10.1016/j. concog.2011.02.005

Carr L, Iacoboni M, Dubeau M-C, Mazziotta JC, Lenzi GL (2003) Neural mechanisms of empathy in humans: a relay from neural systems for imitation to limbic areas. Proc Natl Acad Sci USA 100(9):5497-5502. doi:10.1073/pnas.0935845100

Cashdan E (1998) Are men more competitive than women? Brit J Soc Psychol 37(Pt 2):213-229. Retrieved from http://europepmc.org/ abstract/MED/9639863

Castano E, Yzerbyt V, Paladino M-P, Sacchi S (2002) I belong, therefore, I exist: ingroup identification, ingroup entitativity, and ingroup bias. Pers Soc Psychol Bull 28(2):135-143. doi: $10.1177 / 0146167202282001$

Cattaneo L, Rizzolatti G (2009) The mirror neuron system. Arch Neurol 66(5):557-560. doi:10.1001/archneurol.2009.41

Clark RD, Hatfield E (1989) Gender differences in receptivity to sexual offers. J Psychol Hum Sex 2(1):39-55. Retrieved from http:// www.tandfonline.com/doi/abs/10.1300/J056v02n01_04

Cochin S, Barthelemy C, Lejeune B, Roux S, Martineau J (1998) Perception of motion and qEEG activity in human adults.
Electroencephalogr Clin Neurophysiol 107(4):287-295. Retrieved from http://www.sciencedirect.com/science/article/pii/ S0013469498000716

Colzato LS, de Bruijn ERA, Hommel B (2012a) Up to "me" or up to "us"? The impact of self-construal priming on cognitive self-other integration. Front Psychol 3:341. doi:10.3389/ fpsyg.2012.00341

Colzato LS, Zech H, Hommel B, Verdonschot R, van den Wildenberg WPM, Hsieh S (2012b) Loving-kindness brings loving-kindness: the impact of Buddhism on cognitive self-other integration. Psychon Bull Rev 19(3):541-545. doi:10.3758/s13423-012-0241-y

Colzato LS, van den Wildenberg WPM, Hommel B (2013) Increasing self-other integration through divergent thinking. Psychon Bull Rev 20(5):1011-1016. doi:10.3758/s13423-013-0413-4

Craft JL, Simon JR (1970) Processing symbolic information from a visual display: Interference from an irrelevant directional cue. J Exp Psychol 83(3, Pt.1):415-420. doi:10.1037/h0028843

Davis MH (1980) A multidimensional approach to individual differences in empathy. JSAS Cat Sel Doc Psychol 10:85

Davis MH (1983) Measuring individual differences in empathy: evidence for a multidimensional approach. J Pers Soc Psychol 44(1):113-126

Decety J, Lamm C (2011) Empathy versus personal distress: recent evidence from social neuroscience. In: The social neuroscience of empathy, pp 199-213. Retrieved from http://books.google. com/books?hl=nl\&lr=\&id=KLvJKTN_nDoC\&pgis $=1$

Decety J, Sommerville JA (2003) Shared representations between self and other: a social cognitive neuroscience view. Trends Cogn Sci 7(12):527-533. doi:10.1016/j.tics.2003.10.004

Dittrich K, Rothe A, Klauer KC (2012) Increased spatial salience in the social Simon task: a response-coding account of spatial compatibility effects. Atten Percept Psychophys 74(5):911-929. doi:10.3758/s13414-012-0304-1

Dolk T, Hommel B, Colzato LS, Schütz-Bosbach S, Prinz W, Liepelt R (2011) How "social" is the social Simon effect? Front Psychol 2:84. doi:10.3389/fpsyg.2011.00084

Dolk T, Hommel B, Prinz W, Liepelt R (2013) The (not so) social Simon effect: a referential coding account. J Exp Psychol Hum Percept Perform 39(5):1248-1260. Retrieved from http://www. ncbi.nlm.nih.gov/pubmed/23339346

Dolk T, Hommel B, Colzato LS, Schütz-Bosbach S, Prinz W, Liepelt R (2014) The joint Simon effect: a review and theoretical integration. Front Psychol 5:974. doi:10.3389/fpsyg.2014.00974

Duncan LA, Park JH, Faulkner J, Schaller M, Neuberg SL, Kenrick DT (2007) Adaptive allocation of attention: effects of sex and sociosexuality on visual attention to attractive oppositesex faces. Evol Hum Behav 28(5):359-364. doi:10.1016/j. evolhumbehav.2007.05.001

Ferraro L, Iani C, Mariani M, Milanese N, Rubichi S (2011) Facilitation and interference components in the joint Simon task. Exp Brain Res 211(3-4):337-343. doi:10.1007/s00221-011-2711-2

Ford RM, Aberdein B (2015) Exploring social influences on the joint Simon task: empathy and friendship. Front Psychol 6:962. doi:10.3389/fpsyg.2015.00962

Freischlag J (1973) A comparison of the effects of sex, competition, and ability on a perceptual motor task. Res Q Am Assoc Health Phys Educ Recreat 44(2):178-184. doi:10.1080/10671188.1973. 10615193

Frith C (2005) The neural basis of hallucinations and delusions. Compte Rendus Biol 328(2):169-175

Gallese V, Goldman AI (1998) Mirror neurons and the simulation theory of mind-reading. Trends Cogn Sci 2(12):493-501. doi:10.1016/S1364-6613(98)01262-5

Goldman AI (1989) Interpretation psychologized. Mind Lang 4(3):161-185. doi:10.1111/j.1468-0017.1989.tb00249.x 
Goldman AI (2009) Mirroring, simulating and mindreading. Mind Lang 24(2):235-252. doi:10.1111/j.1468-0017.2008.01361.x

Hajcak G, Molnar C, George MS, Bolger K, Koola J, Nahas Z (2007) Emotion facilitates action: a transcranial magnetic stimulation study of motor cortex excitability during picture viewing. Psychophysiology 44(1):91-97. doi:10.1111/j.1469-8986.2006.00487.x

Hanssen M, Bak M, Bijl RV, Vollebergh W, van Os J (2005) The incidence and outcome of subclinical psychotic experiences in the general population. Br J Clin Psychol 44(2):181-191. doi:10.134 8/014466505X29611

Hari R, Forss N, Avikainen S, Kirveskari E, Salenius S, Rizzolatti G (1998) Activation of human primary motor cortex during action observation: a neuromagnetic study. Proc Natl Acad Sci 95(25):15061-15065. doi:10.1073/pnas.95.25.15061

Hauser M, Knoblich G, Repp BH, Lautenschlager M, Gallinat J, Heinz A, Voss M (2011) Altered sense of agency in schizophrenia and the putative psychotic prodrome. Psychiatry Res 186(23):170-176. doi:10.1016/j.psychres.2010.08.003

Hefner K, Whittle N, Juhasz J, Norcross M, Karlsson R-M, Saksida LM, Bussey TJ, Singewald N, Holmes A (2008) Impaired fear extinction learning and cortico-amygdala circuit abnormalities in a common genetic mouse strain. J Neurosci 28(32):8074-8085. doi:10.1523/JNEUROSCI.4904-07.2008

Hommel B (1996) S-R compatibility effects without response uncertainty. Q J Exp Psychol Sect A 49(3):546-571. doi:10.1080/713755643

Humphreys GW, Bedford J (2011) The relations between joint action and theory of mind: a neuropsychological analysis. Exp Brain Res 211(3-4):357-369. doi:10.1007/s00221-011-2643-x

Hur J-W, Kwon JS, Lee TY, Park S (2014) The crisis of minimal selfawareness in schizophrenia: a meta-analytic review. Schizophr Res 152(1):58-64. doi:10.1016/j.schres.2013.08.042

Iacoboni M (2009) Imitation, empathy, and mirror neurons. Annu Rev Psychol 60:653-670. doi:10.1146/annurev. psych.60.110707.163604

Ickes W (1993) Traditional gender roles: Do they make, and then break, our relationships? J Soc Issues 49(3):71-85. doi:10.1111/j.1540-4560.1993.tb01169.x

Johns LC, Rossell S, Frith CD, Ahmad F, Hemsley D, Kuipers E, McGuire PK (2001) Verbal self-monitoring and auditory verbal hallucinations in patients with schizophrenia. Psychol Med 31(4):705-715. doi:10.1017/S0033291701003774

Jones SR, de Wit L, Fernyhough C, Meins E (2008) A new spin on the Wheel of Fortune: priming of action-authorship judgements and relation to psychosis-like experiences. Conscious Cogn 17(3):576-586. doi:10.1016/j.concog.2007.08.008

Karremans JC, Verwijmeren T (2008) Mimicking attractive oppositesex others: the role of romantic relationship status. Pers Soc Psychol Bull 34(7):939-950. doi:10.1177/0146167208316693

Kilner JM, Friston KJ, Frith CD (2007) Predictive coding: an account of the mirror neuron system. Cogn Process 8(3):159-166. doi:10.1007/s10339-007-0170-2

Klempova B, Liepelt R (2015) Do you really represent my task? Sequential adaptation effects to unexpected events support referential coding for the joint Simon effect. Psychol Res. doi:10.1007/s00426-015-0664-y

Lamm C, Batson CD, Decety J (2007a) the neural substrate of human empathy: effects of perspective-taking and cognitive appraisal. J Cogn Neurosci 19(1):42-58. Retrieved from http://www.mitpressjournals.org/doi/abs/10.1162/jocn.2007.19.1.42\#.U0T4gKh_t8E

Lamm C, Batson CD, Decety J (2007b) The neural substrate of human empathy: effects of perspective-taking and cognitive appraisal. J Cogn Neurosci 19(1):42-58. doi:10.1162/jocn.2007.19.1.42

Leitenberg H, Henning K (1995) Sexual fantasy. Psychol Bull 117(3):469-496
Liepelt R, Schneider JC, Aichert DS, Wöstmann N, Dehning S, Möller H-J, Riedel M, Dolk T, Ettinger U (2012) Action blind: disturbed self-other integration in schizophrenia. Neuropsychologia 50(14):3775-3780. doi:10.1016/j.neuropsychologia.2012.10.027

Maeda T, Kato M, Muramatsu T, Iwashita S, Mimura M, Kashima H (2012) Aberrant sense of agency in patients with schizophrenia: forward and backward over-attribution of temporal causality during intentional action. Psychiatry Res 198(1):1-6. doi:10.1016/j. psychres.2011.10.021

McClung JS, Jentzsch I, Reicher SD (2013) Group membership affects spontaneous mental representation: failure to represent the out-group in a joint action task. PLoS One 8(11):e79178. doi:10.1371/journal.pone.0079178

Meyer M, Hunnius S, van Elk M, van Ede F, Bekkering H (2011) Joint action modulates motor system involvement during action observation in 3-year-olds. Exp Brain Res 211(3-4):581-592. doi:10.1007/s00221-011-2658-3

Michalska KJ, Kinzler KD, Decety J (2013) Age-related sex differences in explicit measures of empathy do not predict brain responses across childhood and adolescence. Dev Cogn Neurosci 3:22-32. doi:10.1016/j.den.2012.08.001

Mishara AL, Lysaker PH, Schwartz MA (2014) Self-disturbances in schizophrenia: history, phenomenology, and relevant findings from research on metacognition. Schizophr Bull 40(1):5-12. doi: $10.1093 /$ schbul/sbt169

Mogenson G, Jones D, Yim C (1980) From motivation to action: functional interface between the limbic system and the motor system. Prog Neurobiol 14(2-3):69-97. doi:10.1016/0301-0082(80)90018-0

Muigg P, Hetzenauer A, Hauer G, Hauschild M, Gaburro S, Frank E, Landgraf R, Singewald N (2008) Impaired extinction of learned fear in rats selectively bred for high anxiety-evidence of altered neuronal processing in prefrontalamygdala pathways. Eur J Neurosci 28(11):2299-2309. doi:10.1111/j.1460-9568.2008.06511.x

Mukamel R, Ekstrom AD, Kaplan J, Iacoboni M, Fried I (2010) Single-neuron responses in humans during execution and observation of actions. Curr Biol 20(8):750-756. Retrieved from http://www.sciencedirect.com/science/article/pii/ S0960982210002332

Müller BCN, Brass M, Kühn S, Tsai C-C, Nieuwboer W, Dijksterhuis A, van Baaren RB (2011a) When Pinocchio acts like a human, a wooden hand becomes embodied. Action co-representation for non-biological agents. Neuropsychologia 49(5):1373-1377. doi:10.1016/j.neuropsychologia.2011.01.022

Müller BCN, Kühn S, van Baaren RB, Dotsch R, Brass M, Dijksterhuis A (2011b) Perspective taking eliminates differences in corepresentation of out-group members' actions. Exp Brain Res 211(3-4):423-428. doi:10.1007/s00221-011-2654-7

Müller BCN, Oostendorp AK, Kühn S, Brass M, Dijksterhuis A, van Baaren RB (2015) When triangles become human: action co-representation for objects. Interact Stud 16(1):54-67. doi:10.1075/ is. $16.1 .03 \mathrm{mul}$

Mussi DR, Marino BFM, Riggio L (2015) Experimental psychology simon effect the influence of social and nonsocial variables on the Simon effect. Exp Psychol. doi:10.1027/1618-3169/a000292

Nelson B, Parnas J, Sass LA (2014) Disturbance of minimal self (ipseity) in schizophrenia: clarification and current status. Schizophr Bull. doi:10.1093/schbul/sbu034

Obhi SS, Sebanz N (2011) Moving together: toward understanding the mechanisms of joint action. Exp Brain Res 211(3-4):329336. doi:10.1007/s00221-011-2721-0

Ocampo B, Kritikos A (2011) Interpreting actions: the goal behind mirror neuron function. Brain Res Rev 67(1-2):260-267. doi:10.1016/j.brainresrev.2011.03.001

Petersen JL, Hyde JS (2010) A meta-analytic review of research on gender differences in sexuality, 1993-2007. Psychol Bull 136(1):21-38 
Philipp AM, Prinz W (2010) Evidence for a role of the responding agent in the joint compatibility effect. Q J Exp Psychol 63(11):2159-2171. doi:10.1080/17470211003802426

Powlishta KK (1995) Intergroup processes in childhood: social categorization and sex role development. Dev Psychol 31(5):781-788

Ratcliff R (1993) Methods for dealing with reaction time outliers. Psychol Bull 114(3):510-532

Renes RA, van der Weiden A, Prikken M, Kahn RS, Aarts H, van Haren NEM (2015) Abnormalities in the experience of selfagency in schizophrenia: a replication study. Schizophr Res 164(1):210-213. doi:10.1016/j.schres.2015.03.015

Rizzolatti G, Craighero L (2005) Mirror neuron: a neurological approach to empathy. In: Changeux J-P, Damasio AR, Singer W, Christen Y (eds) Neurobiology of human values. Springer, Berlin, pp 107-123. doi:10.1007/3-540-29803-7

Ruys KI, Aarts H (2010) When competition merges people's behavior: interdependency activates shared action representations. J Exp Soc Psychol 46(6):1130-1133. doi:10.1016/j.jesp.2010.05.016

Sartori L, Betti S (2015) Complementary actions. Front Psychol 6:557. doi: $10.3389 /$ fpsyg. 2015.00557

Sebanz N, Knoblich G, Prinz W (2003) Representing others' actions: just like one's own? Cognition 88(3):B11-B21. doi:10.1016/S0

Sellaro R, Dolk T, Colzato LS, Liepelt R, Hommel B (2015) Referential coding does not rely on location features: evidence for a nonspatial joint Simon effect. J Exp Psychol Hum Percept Perform 41(1):186-195

Slotter EB, Gardner WL (2009) Where do you end and I begin? Evidence for anticipatory, motivated self-other integration between relationship partners. J Pers Soc Psychol 96(6):1137-1151

Stefanis NC, Hanssen M, Smirnis NK, Avramopoulos DA, Evdokimidis IK, Stefanis CN, Verdoux H, van Os J (2002) Evidence that three dimensions of psychosis have a distribution in the general population. Psychol Med 32(02):347-358. doi:10.1017/S0033291701005141

Stenzel A, Chinellato E, Bou MAT, del Pobil ÁP, Lappe M, Liepelt $\mathrm{R}$ (2012) When humanoid robots become human-like interaction partners: corepresentation of robotic actions. J Exp Psychol Hum Percept Perform 38(5):1073-1077. doi:10.1037/a0029493
Stenzel A, Chinellato E, Del Pobil AP, Lappe M, Liepelt R (2013) How deeply do we include robotic agents in the self? Int J Humanoid Rob 10(01):1350015. doi:10.1142/ S0219843613500151

Stenzel A, Dolk T, Colzato LS, Sellaro R, Hommel B, Liepelt R (2014) The joint Simon effect depends on perceived agency, but not intentionality, of the alternative action. Front Hum Neurosci 8:595. doi:10.3389/fnhum.2014.00595

Sugimori E, Asai T, Tanno Y (2011) Sense of agency over thought: external misattribution of thought in a memory task and proneness to auditory hallucination. Conscious Cogn 20(3):688-695. doi:10.1016/j.concog.2010.12.014

Valdesolo P, DeSteno D (2011) Synchrony and the social tuning of compassion. Emotion 11(2):262-266

Van der Weiden A, Prikken M, van Haren NEM (2015) Selfother integration and distinction in schizophrenia: a theoretical analysis and a review of the evidence. Neurosci Biobehav Rev 57:220-237. doi:10.1016/j.neubiorev.2015.09.004

Van Hooff JC, Crawford H, van Vugt M (2011) The wandering mind of men: ERP evidence for gender differences in attention bias towards attractive opposite sex faces. Soc Cogn Affect Neurosci 6(4):477-485. doi:10.1093/scan/nsq066

Vesper C, van der Wel RPRD, Knoblich G, Sebanz N (2011) Making oneself predictable: reduced temporal variability facilitates joint action coordination. Exp Brain Res 211(3-4):517-530. doi:10.1007/s00221-011-2706-Z

Vlainic E, Liepelt R, Colzato LS, Prinz W, Hommel B (2010) The virtual co-actor: the social Simon effect does not rely on online feedback from the other. Front Psychol 1:208. doi:10.3389/ fpsyg.2010.00208

Wiltermuth SS, Heath C (2009) Synchrony and cooperation. Psychol Sci 20(1):1-5. doi:10.1111/j.1467-9280.2008.02253.x

Zhang Z, Deng Z (2014) Human gender differences in cognitive preferences toward attractive faces in a visual oddball paradigm: an ERP study. In: Sun F, Hu D, Liu H (eds) Foundations and practical applications of cognitive systems and information processing, vol 215. Springer, Berlin, Berlin, pp 109-120. doi:10.1007/978-3-642-37835-5 